\title{
GRADUAÇÃO EM SAÚDE, UMA REFLEXÃO SOBRE ENSINO-APRENDIZADO
}

\author{
UNDERGRADUATE EDUCATION IN HEALTH, A REFLECTION ON TEACHING-LEARNING
}

GRADUACIÓN EN SALUD, UNA REFLEXIÓN SOBRE ENSEÑANZA-APRENDIZAJE

Iramara Lima Ribeiro ${ }^{1}$

Antônio Medeiros Júnior ${ }^{2}$

Resumo $\mathrm{O}$ ensino superior em saúde exerce papel fundamental na sociedade porque os egressos dos cursos ofertados na área serão os futuros prestadores de assistência à população. O objetivo deste estudo foi analisar publicações na literatura a respeito da graduação na área da saúde, cuja metodologia foi uma revisão narrativa, com 51 materiais selecionados na base de dados da Biblioteca Virtual em Saúde (enfocados na graduação, metodologias de ensino e relação teoria-prática). Os resultados mostraram a importância de atrelar teoria e prática e divergências em relação às metodologias de ensino, com a necessidade de um olhar crítico sobre elas, além de fragilidades na formação pedagógica de docentes. Conclui-se que o dissenso quanto às metodologias de ensino e a preocupação com a formação de discentes e docentes mostra a necessidade de realizar debates de modo a socializar experiências e ideias nesse importante campo do conhecimento que deem respostas às necessidades sociais.

Palavras-chave ensino superior; instituições de ensino superior; atenção à saúde.
Abstract Higher education in health plays a fundamental role in society because the graduates of the courses offered in this area will be the future providers of care to the population. This study aimed to analyze publications in the literature regarding undergraduate work in health, the methodology of which was a narrative review, with 51 stories selected in the Virtual Library in Health database (focused on undergraduate education, teaching methods, and the theory-practice relation). The results showed the importance of connecting theory and practice, the differences in teaching methodologies - which must be analyzed critically -, and the weaknesses in the pedagogical training of teachers. It was concluded that the dissent with regard to the teaching methodologies and concern with the training of teachers and students shows the need for discussions to socialize experiences and ideas in this important field of knowledge and to meet social needs.

Keywords Higher education; higher education institutions; health care. 


\section{Introdução}

A educação superior tem como papel fundamental formar a elite intelectual e científica, cabendo às universidades, em seu papel de instituições, o compromisso de gerar saberes voltados às ações que envolvam aspectos relevantes para a sociedade. Desde a década de 1920, “o debate sobre a criação de universidades não se restringia mais a questões estritamente políticas (grau de controle estatal) como no passado, mas ao conceito de universidade e suas funções na sociedade" (Martins, 2002, p. 4). Contudo, predominam critérios utilitaristas nas raízes da expansão do ensino superior, voltados para o mercado e atendendo interesses de um pequeno grupo (Colossi, Consentino e Queiroz, 2001).

Em relação à graduação em saúde, a maioria das disciplinas tem sido desenvolvida pelo repasse de conteúdos, confundindo-se o conhecimento com a informação memorizada. Assim, há necessidade de mudanças que conduzam à integração entre ensino e pesquisa, viabilizadas pelos projetos político-pedagógicos dos cursos (Nóbrega-Therrien e Feitosa, 2010), além da integração com a extensão para que os graduandos estabeleçam elos entre os seus cursos e os futuros campos de atuação profissional. Cabe ao Estado articular o oferecimento de cursos, compatibilizando-os às demandas sociais e, para tal, são necessárias iniciativas de valorização de profissionais da educação (Franco, 2008), de maneira a formar alunos em consonância com as necessidades da sociedade e, ao mesmo tempo, promover uma formação crítico-reflexiva.

Segundo Giroux (2010), há consenso mundial entre acadêmicos de que o ensino superior está em estado de crise, e para educar jovens capazes de enfrentar os problemas da nação e do mundo, é preciso

desafiar a existência de fronteiras disciplinares rígidas, o culto da especialização ou de conhecimentos altamente especializados alheios à vida pública, e ideologias antidemocráticas que zombam do exercício da liberdade acadêmica (Giroux, 2010, p. 28).

\section{Objetivo e percurso metodológico}

O objetivo deste estudo 3 foi analisar publicações na literatura a respeito da graduação na área da saúde, de modo a permitir uma reflexão sobre ensino-aprendizado. Realizou-se uma revisão bibliográfica do tipo narrativa, em que a proposta do artigo foi não a análise baseada em evidências, e sim refletir a respeito do tema. Conforme Bernardo, Nobre e Jatene (2004), na revisão narrativa as escolhas textuais são realizadas a partir do que o pesquisador 
julga relevante. Apresenta como desvantagem a não menção de onde as informações foram coletadas, podendo conduzir a viés de seleção. De modo a evitar tal viés, foi feita uma busca de materiais com critérios preestabelecidos, conforme descrito adiante.

A busca ocorreu na base de dados eletrônica Biblioteca Virtual em Saúde, nos dias 22 de maio de 2011 e 3 de janeiro de 2013, uma vez que ela reúne materiais de outras bases de dados tanto nacionais quanto internacionais.

O método adotado foi o integrado, isto é, digitando-se na caixa de texto o descritor 'ensino superior', pesquisado nos descritores em ciências da saúde, obtendo-se 2.684 resultados. Este método permite que, após a apresentação dos resultados, a pesquisa possa ser refinada (Bireme, 2009). Desse modo, houve refinamento para publicações entre 2001 e 2013 que estivessem nos idiomas português, espanhol e inglês (variáveis de seleção), restando 1.909 resultados. Prosseguiu-se com a leitura dos títulos, resumos e/ou palavras-chave em busca de termos relacionados com: formação, graduação, educação, academia, docência, portfólio, ensino, aprendizado, problematização, práticas pedagógicas, transformação social, comunidade, necessidades dos serviços e interdisciplinaridade. Desta etapa resultaram 123 materiais.

Após esta fase, seguiu-se uma segunda etapa de leitura dos textos na íntegra e cujos critérios de elegibilidade foram conter enfoque para a graduação, metodologias de ensino e relação teoria-prática, resultando em 51 referências entre 2002 e 2012. Salientamos que esta revisão narrativa fez parte da revisão bibliográfica de uma dissertação de mestrado.

\section{As publicações sobre graduação em saúde}

Em relação ao perfil das 51 referências selecionadas, 64,7\% da produção estava situada entre 2011 e 2012, demonstrando que este é um tema pertinente e que vem ganhando discussão no meio científico. Apesar da seleção não ter considerado a origem dos estudos, 45 referências (88\%) apresentaram autores provenientes de instituições brasileiras (40 artigos - tabela 1, três dissertações e duas teses - tabela 3). Por esta razão, houve enfoque para o contexto brasileiro. Também foram selecionados seis artigos oriundos da Espanha, Argentina, Colômbia, Canadá e Portugal (Tabela 2). 
Tabela 1

Artigos selecionados com pesquisadores de instituições brasileiras, segundo autor (es), ano, e indexador.

\begin{tabular}{|c|c|c|c|c|c|}
\hline Autor (es) & Ano & Indexador & Autor (es) & Ano & Indexador \\
\hline Associação Brasileira de Ensino e & 2011 & Lilacs & Lemos, M.; Bazzo, L.M.F. & 2010 & Lilacs \\
\hline \multicolumn{6}{|l|}{ Pesquisa em Serviço Social } \\
\hline & & & Machado, J.L.M.; Machado, V.M.; & 2011 & Lilacs \\
\hline Bagnato, M.H.S.; Rodrigues, R.M. & 2007 & Lilacs & Vieira, J.E. & & \\
\hline Barba, P.C.S.D. et al. & 2012 & Lilacs & Mendes, L.C.B.; Caprara, A. & 2012 & Lilacs \\
\hline Bicalho, R.N.M.; Oliveira, M.C.S.L. & 2012 & Lilacs & Moraes, J.T.; Lopes, E.M.T. & $2009-2010$ & Lilacs \\
\hline Bruzos, G.A.S. et al. & 2011 & Lilacs & $\begin{array}{l}\text { Nunes, E.C.D.A.; Silva, L.W.S.; Pires, } \\
\text { E.P.O.R. }\end{array}$ & 2011 & $\begin{array}{l}\text { Lilacs/BDENF - } \\
\text { enfermagem (Brasil) }\end{array}$ \\
\hline \multirow[t]{2}{*}{ Calderón, A.I.; Pedro, R.F.; Vargas, M.C. } & 2011 & Lilacs & & & \\
\hline & & & Oliveira, C.C.; Vasconcellos, M.M.M. & 2011 & Lilacs \\
\hline \multirow[t]{2}{*}{ Camponogara, S. et al. } & 2012 & Lilacs/BDENF - & & & \\
\hline & & enfermagem (Brasil) & Patrício, Z.M. & 2011 & Lilacs \\
\hline Canalli, C.S.E. et al. & 2011 & BBO - odontologia (Brasil) & Pereira, J.G. et al. & 2009 & Lilacs \\
\hline Cardoso, F.A. et al. & 2011 & Lilacs & Pereira, S.E. & 2007 & Lilacs \\
\hline Correia, A.A. et al. & 2009 & Lilacs & Pereira, W.R. & 2011 & Lilacs \\
\hline Costa, C.; Casagrande, L.D.R.; Ueta, J. & 2009 & Lilacs & Rodrigues, C. & 2012 & Lilacs \\
\hline Cyrino, E.G.; Toralles-Pereira, M.L. & 2004 & Lilacs & Rojo, P.T. et al. & 2011 & $\begin{array}{c}\text { Lilacs / BDENF - } \\
\text { enfermagem (Brasil) }\end{array}$ \\
\hline \multirow[t]{2}{*}{ Fernandes, J.D. et al. } & 2005 & Lilacs/BDENF - & & & \\
\hline & & enfermagem (Brasil) & Lima, J.O. R. et al. & 2011 & Lilacs \\
\hline Formiga, N.F.B.; Ribeiro, K.S.Q.S. & 2012 & Lilac Express & Silva, K.L. et al. & 2012 & Lilacs \\
\hline Francischetti, I. et al. & 2011 & Lilacs & Silva, M.A.M. et al. & 2012 & Lilacs \\
\hline Franco, A.C.; Boog, M.C.F. & 2007 & Lilacs & Silva, R.H.A.; Miguel, S.S.; Teixeira, L.S. & 2011 & Lilacs \\
\hline Garcia, M.A.A.; Silva, A.L.B. & 2011 & Lilacs & Soares, N.T.; Aguiar, A.C. & 2010 & Lilacs Express \\
\hline \multirow[t]{2}{*}{ Gomes, J.B.; Casagrande, L.D.R. } & 2002 & $\begin{array}{c}\text { Lilacs / BDENF - } \\
\text { enfermagem (Brasil) }\end{array}$ & Toassi, R.F.C. et al. & 2012 & Lilacs \\
\hline & & & Trajman, A. et al. & 2009 & Lilacs \\
\hline \multirow[t]{2}{*}{ Durán González, A.; Almeida, M.J. } & 2008 & Lilacs & & & \\
\hline & & & Xavier, A.S.; Koifman, L. & 2011 & Lilacs \\
\hline Kruse, M.H.L. & 2008 & $\begin{array}{l}\text { Lilacs / BDENF - } \\
\text { enfermagem (Brasil) }\end{array}$ & & & \\
\hline
\end{tabular}

Fonte: Os autores. 
Tabela 2

\begin{tabular}{|c|c|c|c|}
\hline Autor (es) & Ano & País & Indexador \\
\hline Hinojo, M.A.; Fernández, A. & 2012 & Espanha & Lilacs \\
\hline Eder, M.L.; Schwartzman, G. & 2011 & Argentina & Lilacs \\
\hline Murrain Knudson, E. & 2009 & Colômbia & Lilacs \\
\hline Pocinho, M.; Fragoeiro, J.G. & 2012 & Portugal & Lilacs Express \\
\hline Vieira, D.A.; Caires, S.; Coimbra, J.L. & 2011 & Portugal & Lilacs \\
\hline Klegeris, A.; Hurren, $\mathrm{H}$. & 2011 & Canadá & Medline \\
\hline
\end{tabular}

Fonte: Os autores.

Tabela 3

Dissertações e teses selecionadas, originárias de programas de pós-graduação brasileiros, segundo autor, ano e indexador.

\begin{tabular}{lcc}
\hline Autor (es) & Ano & Indexador \\
\hline Dias, H.S. & Dissertações & Lilacs \\
Marsden, M. & 2011 & Lilacs \\
Vilardo, C.O.L. & 2009 & Lilacs \\
& Teses & \\
Gomes, A.P. & Gomes, A.P. & Lilacs \\
Silva, A.P.S. & Silva, A.P.S. & Lilacs \\
\hline
\end{tabular}

Fonte: Os autores. 
A base de dados que mais indexou os textos foi a Lilacs (Literatura Latino-Americana e do Caribe em Ciências da Saúde), com 47 resultados, dos quais seis também estavam indexados na Base de Dados de Enfermagem (BDENF), três resultados estavam na Lilacs Express, um na Medical Literature Analysis and Retrieval System Online (Medline) e um na Bibliografia Brasileira de Odontologia (BBO).

Após a leitura, foram identificados os principais assuntos abordados nos textos, gerando o agrupamento deles em três tópicos para compor a revisão - Formação no ensino superior: processos e embates; Educar para integrar: dividir, somar, multiplicar; A vez dos alunos: Inovações e atitudes transformadoras.

\section{Formação no ensino superior: processos e embates}

A educação em saúde no Brasil vem sendo pautada pelo modelo tradicional, tendo as instituições de ensino superior (IES), segundo Lemos e Bazzo (2010), voltado o ensino na graduação para aparelhos e sistemas orgânicos, além de tecnologias altamente especializadas, não acompanhando as transformações nos serviços de saúde. Neste sentido, as universidades devem preparar os alunos para aprender a aprender, o trabalho em equipe, a comunicação, a agilidade frente às situações e a capacidade propositiva (Moraes e Lopes, 2010).

Nas décadas de 1980 e 1990 existia no Brasil um movimento interno de rompimento com a formação em saúde baseada apenas no modelo clínico vigente, efetivado na constituição de 1988 e na posterior organização do Sistema Único de Saúde. Contudo, ao invés de assumir destaque central nas diretrizes curriculares, tal movimento foi secundarizado em detrimento das deliberações de instituições internacionais, tais como: o Banco Mundial, que propunha o distanciamento do Estado no fornecimento da educação superior, com extensão da oferta por instituições privadas; a Unesco (Organização das Nações Unidas para a Educação, a Ciência e a Cultura) e a Organização Mundial de Saúde, numa ótica diferente, que inspiravam muitos princípios pedagógicos (Bagnato e Rodrigues, 2007).

Conforme Calderón, Pedro e Vargas (2011), a Unesco se opunha ao Banco Mundial, defendendo a presença e a responsabilidade do Estado pelo ensino superior, mas em 2009 passou a incorporar e aceitar o neoliberalismo na educação, "adaptando-se ao que parece ser irreversível: a vitória da educação como serviço comercial no âmbito da Organização Mundial do Comércio" (Calderón, Pedro e Vargas, 2011, p. 1.186).

O ensino superior foi, portanto, se encaminhando para uma formação de competências específicas e de modo acrítico, suprindo a mão de obra do mercado, proporcionando o contato dos estudantes com o campo de trabalho 
nos estágios curriculares. Vieira, Caires e Coimbra (2011) consideram o estágio como propulsor do desenvolvimento de confiança para a busca de emprego, negociar apoios e barreiras durante o processo de adaptação ao trabalho e aumentar o conhecimento acerca de si próprio e do mundo do trabalho.

Todavia, quando o estudante é apenas 'lançado' num estágio, já no fim de sua graduação, dificilmente desenvolverá habilidades que o leve a assumir uma postura autônoma, mas não autossuficiente, sabendo dialogar com o outro, crescendo com as opiniões divergentes da sua. Os benefícios a partir do contato de graduandos com ambientes extrauniversitários, potencializando o saber, devem ocorrer ao longo da formação e não apenas em momentos pontuais. Para tal, há necessidade de revisão e discussão constantes das metodologias de ensino para que a graduação ocorra no tempo devido a uma formação em consonância com as necessidades populacionais. Teorizar e praticar são imperativos em qualquer formação, e pensando conforme Eder e Schwartzman (2011), boas teorias não são necessariamente derivações práticas, mas somente estas permitem a construção de um aspecto diferente.

Xavier e Koifman (2011) abordam a questão atual da flexibilização excessiva dos currículos e redução da carga horária mínima para os cursos de graduação, aumentando a disputa entre os conteúdos necessários à integralização dos cursos e prejudicando a aproximação deles a uma realidade profissional.

Considerando as mudanças necessárias na formação em saúde, as políticas públicas apontam para a implementação de currículos integrados e voltados às demandas da população, modificados a partir da prática para produzir a aprendizagem (Barba et al., 2012). Então, é indispensável romper estruturas rígidas nas universidades, iniciando pela interação entre o corpo acadêmico, os serviços e as comunidades. A formação profissional não deve se limitar aos conhecimentos especializados, e sim agregar saberes de outros campos, respeitando-se as competências específicas de cada profissão, como forma de superar obstáculos e proporcionar uma atenção à saúde empenhada com a igualdade de direitos e a justiça social.

Vemos até aqui, entre os estudos incluídos neste tópico, certo consenso quanto à necessidade de mudanças no reordenamento do ensino superior. Ressalva-se que o processo de reformulação do ensino brasileiro com currículos mais flexíveis ocorreu a partir de 1996, quando o governo sancionou a Lei de Diretrizes e Bases para a Educação (Brasil, 1996), reorientando os cursos de graduação em saúde a partir de 2001 por meio das Diretrizes Curriculares Nacionais (DCN). A partir de então, foi permitido que as escolas adaptassem seu próprio currículo às suas realidades regionais (Teixeira, Coelho e Rocha, 2013).

Apesar disso, Conterno e Lopes (2013) julgam que as DCN, em oposição ao ensino tradicional (conhecido por proporcionar um ensino fragmentado e especializado), apresentam como pressuposto a adoção de metodologias 
inovadoras ou ativas, transformadas em 'prescrições pedagógicas', ao longo dos anos, pela falta de reflexão a respeito dos aspectos teóricos que as embasaram, sendo preciso sair do enfoque central da discussão metodológica para a epistemológica.

Kruse (2008, p. 351) observa a preocupação em seguir rigidamente as políticas educacionais porque as palavras “aprender a aprender, que engloba aprender a ser, aprender a fazer, aprender a viver juntos e aprender a conhecer (...) formação generalista, humanista, crítica e reflexiva (...) competências, habilidades e conteúdos" não garantem uma boa formação, havendo necessidade de os docentes que adotam a formação de alunos críticos e reflexivos exercerem a criticidade, a começar pelas DCN.

Como fazer então? Como articular a educação do profissional de saúde, sua formação e ampliar a sua atuação, (...) considerando que desejamos novos agentes sociais, que, a partir de novos esquemas de pensamento, desenvolvam novos modos de operar e agir? Certamente mudanças pedagógicas isoladas - centradas meramente no(s) método(s) - não bastam (Gomes, 2011, p. 94).

Seria ingênuo pensar que a formação educativa ocorre somente em campo, sem uma formação sólida na área (Franco e Boog, 2007). Dotar o ensino com temas em consonância com as transformações sociais requer uma constante reavaliação dos cursos da graduação, mas em nossa revisão narrativa encontramos lacunas em relação a conteúdos de ensino na graduação em saúde.

$\mathrm{Na}$ entrevista de Camponogara et al. (2012) com 24 acadêmicos da área da saúde (medicina, fisioterapia, fonoaudiologia, farmácia e odontologia) de uma IES pública do sul do Brasil, os estudantes relataram que temas de meio ambiente são pouco discutidos. De fato, Rodrigues (2012), ao discorrer sobre os currículos de Educação Física, relata que a maioria dos cursos de ensino superior não contempla a efetivação da educação ambiental. Nos achados de Bruzos et al. (2011), aplicando questionário com 75 alunos de Enfermagem, dos quais 36 haviam cursado a disciplina de saúde e meio ambiente, todos relacionaram a Enfermagem com o meio ambiente, enfocando o processo saúde-doença, e a maioria julgou importante uma disciplina que aborde o tema.

Neste pensar, é preciso oportunizar ao aluno uma formação ampliada que envolva a integração com outros saberes, evitando-se uma formação restrita, como a encontrada por Soares e Aguiar (2010), que descobriram como lacunas nas DCN para os cursos de Nutrição questões macro e abrangentes, envolvendo "fatores sociais, econômicos, políticos, agrícolas, comerciais, legais, ecológicos, ambientais, geográficos e culturais, dentre outros" (Soares e Aguiar, 2010, p. 902). Questões desta magnitude precisam estar presentes na formação em saúde porque permeiam aspectos vivenciados 
pelas sociedades e acrescenta-se que tal formação deve instigar o olhar crítico, reflexivo e, ainda, ético nos estudantes.

Ao revelarem dificuldades em relação à formação profissional, os resultados mostram que não basta sancionar políticas públicas, sem concretizá-las mediante ações específicas. As críticas quanto a seguir rigidamente métodos não significam que devemos excluí-los das IES. Pelo contrário, eles devem nortear a construção do saber, adaptados à realidade de cada uma. No entanto, no Portal do Ministério da Educação (Brasil, 2014), para o ensino superior, de nove programas encontrados, apenas três envolviam diretamente estratégias metodológicas: Programa de Reestruturação e Expansão das Universidades Federais: medidas de flexibilização de currículos; Programa de Educação Tutorial: indissociabilidade entre ensino, pesquisa e extensão e educação tutorial na graduação; e Programa de Apoio à Extensão Universitária: apoio no desenvolvimento de programas ou projetos de extensão que contribuam para a implementação de políticas públicas.

Outro problema encontrado nesta revisão foi a oferta de cursos no período noturno desarticulada com os serviços, revelada no estudo de Silva, K. et al. (2012) para a área de enfermagem. Tal situação também ocorre em outros cursos na área da saúde e pode prejudicar o ensino nos serviços, sobretudo nas unidades de saúde porque funcionam, de modo geral, diurnamente. Os serviços que não funcionam no período noturno também necessitam repensar a prestação do cuidado, pois muitos usuários não os acessam devido a estarem em atividades laborais.

As opiniões e lacunas mostradas até aqui revelam que não existem formas completas de conduzir o ensino-aprendizagem. Elas devem ser construídas e reconstruídas envolvendo educadores, educandos, órgãos responsáveis e a sociedade organizada, para que a formação acadêmica não se perca na linha do tempo e tampouco ultrapasse etapas necessárias ao entendimento de novos conceitos na evolução histórica do conhecimento, fundamentada em princípios éticos, na autocrítica e na responsabilidade social em relações interdisciplinares para o enfrentamento de situações variadas e, às vezes, adversas.

A respeito de profissionais egressos estarem aptos ao enfrentamento cotidiano de problemas, Fernandes et al. (2005) trazem a formação por competências como meio de promover uma articulação entre procedimentos técnicos e saberes necessários à resolução e ao enfrentamento de adversidades na relação cultura, sociedade, saúde, ética e educação, com o aluno sujeito do seu processo de formação.

São vistos até então que os modelos antigos de ensino na saúde ainda vigentes não dão conta de tantas transformações sociais, pois não se atualizam na medida em que o mundo se modifica e novas tecnologias surgem. De acordo com Gomes e Casagrande (2002), a racionalidade teórica no ensino da área da saúde é contestada, pois os valores antigos não conseguem 
resolver os problemas existentes e os valores novos ainda não estão firmes, numa dualidade a ser superada pelo diálogo e pelo consenso entre todas as pessoas envolvidas.

Enfatizamos a importância do desprendimento em relação aos saberes e metodologias de ensino mais importantes e adequados às sociedades porque, para alguns, novos modos de formar profissionais da saúde são prementes, num rompimento total com o antigo. $\mathrm{O}$ tradicional pode contribuir com o novo e vice-versa, na medida em que olhar para a tradição permite apropriar-se do que não vem dando certo e do que existe de satisfatório. Olhar para o novo leva ao florescimento de concepções superadoras do que não vem dando respostas ao exercício profissional na área da saúde. Assim, o novo e o antigo deveriam integrar-se de modo a ampliar as formas de ensino e não duelarem como deuses do olimpo e titãs.

\section{Educar para integrar: dividir, somar, multiplicar}

O educar para a saúde numa visão humanizada pode ser visto em analogia a três operações matemáticas: a divisão no sentido de partilhar vivências e saberes entre alunos, professores, profissionais e usuários dos serviços; a soma de pensamentos e esforços consensuais para a melhoria da atenção à saúde; e a multiplicação no enfoque de que saberes devem ser estendidos aos múltiplos indivíduos envolvidos na assistência dos diferentes níveis de atenção à saúde.

Enfatiza-se mais uma vez a importância da teoria vinculada à prática que permita ao educando se posicionar diante do mundo, colocando-se já graduado, numa postura de entendimento da complexidade do ser para quem prestará o cuidado, de modo a estreitar laços e não assumir uma posição de superior, de detentor do saber por conhecer as técnicas de sua profissão. É tempo de se romper com o que Silva, Miguel e Teixeira (2011) chamam de abordagem fundamentada na adesão, na qual o profissional da saúde, autoritariamente, transmite informação a um sujeito passivo, devido à falta de aporte formador para o cuidar com vínculo, identificado na pesquisa de Nunes, Silva e Pires (2011) com 16 acadêmicos do último semestre do curso de graduação em Enfermagem de quatro universidades públicas do Estado da Bahia.

É necessário 'revestir' os estudantes de humanização do cuidado, entendida não como uma aptidão vocacional, mas como uma obrigatoriedade de todos os prestadores de serviços às populações. Todas essas transformações adentram também uma formação continuada e aprofundada dos docentes. Para Francischetti et al. (2011), é preciso um envolvimento docente para fortalecer os processos de formação. Nesse sentido, Pereira (2007) cita que há 
preocupação das instituições com a titulação dos professores e não com a formação deles na área da educação, inexistindo uma sistemática avaliação da prática pedagógica durante a seleção dos docentes. Esta enfatiza mais os currículos, número de artigos publicados e aulas ministradas e não a capacidade comunicativa para problematizar o real, de perfil crítico e reflexivo.

As IES brasileiras, ao priorizarem titulações, encaminham os docentes para a valorização da pesquisa, comprometendo a extensão e o ensino, quando atualmente, segundo Pocinho e Fragoeiro (2012), o professor de ensino superior precisa assumir competências pedagógicas, cognitivas e de conteúdo. Acrescentamos que o docente também carece adotar competências sociais, relacionadas ao saber conviver com o outro, numa relação respeitosa e dialógica. O compromisso com o desenvolvimento da sociedade requer uma mudança dos modos das instituições universitárias pensarem o saber, iniciado por quem ocupa as suas cátedras, sobretudo os docentes, estendendo-se ao corpo discente.

De fato, no estudo descritivo de Garcia e Silva (2011) com 138 docentes de Medicina, houve reclamação por parte destes de que o docente de 40 horas semanais é obrigado a ministrar 20 horas de aula, prejudicando a pesquisa, e que a exigência de produção científica excede em muito as condições oferecidas pela universidade. As autoras inferiram que mais de $40 \%$ deles não participaram da discussão e elaboração do projeto pedagógico. Vemos, então, uma inversão de importância entre ensino e pesquisa. Se no passado a função primordial dos professores era ensinar, atualmente exigem-se deles cada vez mais publicações em detrimento da qualidade e comprometimento com o ensino. "Os docentes têm sido alvo do produtivismo acadêmico instalado nas políticas e ações direcionadas à Educação Superior" (Oliveira e Vasconcellos, 2011, p. 1.020).

Machado, Machado e Vieira (2011), ao analisarem o recrutamento e capacitação de professores para início da docência em cursos da área da saúde de 19 IES, encontraram a adoção de métodos tradicionais como prova didática, prova escrita e entrevista, seguindo o preconizado pela legislação brasileira. Três instituições contornavam o processo seletivo, utilizando grupos tutoriais, situações-problema, paciente-ator, planejamento estratégico e raciocínio clínico e análise de atitudes.

Disto depreende-se que os conselhos universitários superiores necessitam rever a maneira de selecionar professores, de modo a contratar educadores conhecedores de diversificadas metodologias de ensino, proporcionando o diálogo entre saberes e concepções para possibilitar novas formas de interagir com a sociedade.

No estudo de caso de Toassi et al. (2012) a respeito da proposição de um currículo integrado no curso de graduação em Odontologia de uma universidade comunitária no sul do Brasil, segundo os estudantes, os professores 
estavam despreparados, não em relação ao conhecimento técnico, mas para ensinar num currículo integrado. Os autores enfatizam que este problema existe em toda a área da saúde. Estudos pesquisados por Canalli et al. (2011) indicam um ensino bancário na odontologia, com o professor mantendo-se em posição verticalizada em relação ao aluno, desvalorização de habilidades humanísticas, ensino-aprendizagem baseado em exposições orais e, sobretudo, provas teóricas e práticas como métodos de avaliação.

Pelo que vem se mostrando, o ensino não é limitado às técnicas. Envolve valores, habilidades e atitudes, o que, segundo Patrício (2011), exige outras estratégias além daquelas do trabalho de conclusão de curso e de projetos de pesquisa isolados, de modo a gerar conhecimentos e não reproduzi-los. "Ambos, o cuidado e a saúde, podem ser trabalhados no contexto do ensino e no contexto das práticas (...), mas isso só pode ocorrer se os pensarmos a partir de um modelo emancipatório de educação" (Pereira, 2011, p. 984). É essencial ao docente a ação apoiada e realimentada pela teoria num continuum ação-reflexão-ação (Costa, Casagrande e Ueta, 2009).

Esta preocupação com a formação docente presente nos materiais selecionados também é encontrada em outros estudos. Luz e Balzan (2012, p. 12) questionam: "Estamos falando da formação para o ensino ou para a pesquisa?", enfatizando que o ensino tem sido relegado a um segundo plano. Já Calderón (2013), ao abordar a questão da lucratividade das IES privadas, traz outras questões, em que os professores submetem-se a mais de um emprego para obterem mais renda e cumprem cargas horárias rígidas em sala de aula, comprometendo o desenvolvimento de pesquisas e a dedicação às atividades pedagógicas. Somado a isso, refletindo a respeito da docência em saúde, exige-se o conhecimento científico nas áreas de formação profissional, legitimado na prática (Oliveira e Koifman, 2013), numa lógica transmissiva de que saber fazer significa sabe ensinar (Nascimento, Vieira e Araújo, 2012).

Coloca-se, então, o ponto de vista de Lima et al. (2011), vendo o professor não como transmissor, mas como mediador para alcançar o conhecimento. Assim, o ensinar valora o conhecimento prévio do educando para alimentá-lo de novos saberes.

Enquanto os estudantes forem vistos como ignorantes absolutos, jarras vazias que se enchem com o saber transmitido do educador, esses futuros profissionais continuarão a não se comprometer com a sociedade, serão profissionais alienados e massificados (Durán González e Almeida, 2008, p. 27, grifo dos autores).

A importância do poder coletivo, da associação de saberes e da compreensão de valores ganha corpo entre aqueles que acreditam na construção de um mundo mais igualitário e justo. Portanto, as IES precisam avançar em seus planos e projetos, acompanhando e participando do que ocorre para 
além de seus muros. O estabelecimento de parcerias entre o ensino e os serviços não é tarefa fácil porque envolve interesses individuais e coletivos, porém possível quando todos os atores em volta se propõem a dialogar a respeito.

Nesta ótica, tanto as universidades quanto os serviços devem dispor de boa estruturação para aportar os estudantes. Apesar disso, foram encontrados, no material pesquisado, problemas relativos à supervisão de atividades práticas dos alunos em espaço físico reduzido, com carência de recursos, falta de tempo e despreparo profissional (Trajman et al., 2009), além da inversão de papéis, pois os supervisores de campo aproveitavam a chegada de estagiários para reciclar seus conteúdos, pouco contribuindo na orientação destes (Correia et al., 2009).

Todo esse processo formador nos serviços de saúde apenas fará sentido se trouxer benefícios aos seus usuários e comunidade em geral. Desta forma, os estudantes devem ser preparados para verem os usuários em sua totalidade, com suas subjetividades e interações entre espaço e meio social em que vivem. Estar preparado para observar esses fatores certamente proporcionará ao discente um melhor intercâmbio com todos os envolvidos no processo, além de uma formação voltada às necessidades reais do Brasil, como será destacado a seguir.

\section{A vez dos alunos: inovações e atitudes transformadoras}

No cenário mundial atual, é necessário que as universidades reavaliem a formação docente e discente, preparando seres com valores e identidades que contribuam para além da sua área de formação com pequenas ações transformadoras de modo a formar um câmbio social de fortalecimento da saúde e educação (Murrain Knudson, 2009). Tais premissas são passíveis de se consolidarem por meio do estudante posto como ator central do seu ensino/aprendizagem e não como receptor passivo. Existem experiências que têm procurado colocar o aluno em uma postura reflexiva, encontradas nos materiais pesquisados nesta revisão.

No tocante aos conteúdos, destacaram-se como metodologias de ensino a Aprendizagem Baseada em Problemas (PBL, do inglês Problem-Based Learning) e a problematização, cujas bases são construtivistas. Segundo Cyrino e Toralles-Pereira (2004), a Aprendizagem Baseada em Problemas é caracterizada por um elenco de situações, cujos temas são transformados em problemas para serem discutidos em um grupo tutorial, visando à prática, ao passo que na problematização, o aluno é conduzido a estabelecer uma relação dialógica com o professor a partir da vivência de experiências significativas, estando voltada à transformação social, à conscientização de direitos e aos deveres do cidadão e comprometida com uma visão crítica da relação educação e sociedade. 
Mas tais metodologias podem gerar em alguns o ceticismo, e ainda o desconforto, sobretudo quando o ensino ocorre nos serviços passíveis de estruturação inadequada prejudicando seus funcionamentos. Na experiência de Klegeris e Hurren (2011), aplicando a Aprendizagem Baseada em Problemas para o ensino de processos bioquímicos e fisiológicos na Universidade de British Columbia Okanagan, houve resistência do corpo universitário quanto ao método, porém, com o tempo este se tornou confiável entre os discentes e a participação foi maior quando comparada às aulas tradicionais.

Relativo às dificuldades com metodologias problematizadoras, no estudo de Pereira et al. (2009) da experiência de inserção precoce de graduandos em Unidades Básicas de Saúde, os discentes relataram indignação e impotência para tomada de decisão e controle em situações envolvendo miserabilidade, violência, falta de vontade política e vulnerabilidade da população diante das precárias condições de moradia. Positivamente era percebida a importância do trabalho em equipe para desenvolver ações na perspectiva da integralidade.

Encontramos muitos estudos recentes valorizando a aprendizagem nos serviços (Mendes e Caprara, 2012; Cardoso et al., 2011; Dias, 2011; Formiga e Ribeiro, 2012; Silva, 2012; Silva, M. et al., 2012; Vilardo, 2011). De fato, espaços formativos em cenários reais parecem ser mais favoráveis a uma postura de tomada de decisão mais assertiva porque consideram primeiro a estrutura e organização das sociedades para então pensar em estratégias de ações.

Mas será mesmo que o contato com as famílias, equipamentos sociais e comunidade seria capaz de permitir o reconhecimento por parte do aluno da determinação social no processo saúde-doença? Se isso fosse suficiente, mesmo sem a prática profissional no decorrer da graduação, ao iniciar, já graduado, suas atividades em serviço o profissional não deveria conseguir perceber esta relação? (...) Contudo, parece consistente a visão de que sem um espaço de reflexão sobre a prática (...) dificilmente o profissional em formação conseguirá estabelecer relações do que lhe foi apresentado como teoria, com as queixas trazidas pelo paciente e os aspectos psicológicos, culturais, econômicos e históricos que atravessam o cuidado (Marsden, 2009, p. 54).

A aula tradicional, mesmo utilizando aparatos tecnológicos, não garante um bom aprendizado se não for contextualizada e, mesmo assim, se caracteriza apenas por um polo do ensinar, assim como as já citadas problematização e Aprendizagem Baseada em Problemas. Não existe absolutismo nas metodologias e ferramentas de ensino. Elas requerem sinergia umas com as outras para fornecer a maior completude possível na aprendizagem do educando, respeitando-se a sua autonomia. 
Abordando melhor o uso de tecnologias da informação e comunicação (TIC), trazemos o olhar de Hinojo e Fernández (2012) de que elas inovam na educação e levam conhecimento a mais lugares distantes para salvar as pessoas, além de proporcionar aos alunos o compartilhar reflexões e solucionar dificuldades no processo de aprendizado por meio de ambientes virtuais.

No Brasil, o uso das TIC vem tomando força com o Ensino a Distância (EAD). Nele, orientado por um professor-tutor, o aluno realiza seus estudos em qualquer lugar com acesso à rede mundial de computadores, escolhendo o melhor horário para suas leituras e reflexões, com oportunidade de partilhar seus conhecimentos com outros alunos em ambientes virtuais. Julgamos importante mencionar o EAD porque encontramos estudos valorizando-o (Rojo et al., 2011; Bicalho e Oliveira, 2012), e consideramos ser esta uma boa via de ensino por acompanhar as transformações sociais e a era da cibercultura em que vivemos atualmente, podendo ser um método atraente para o educando. Todavia observa-se no Brasil o uso do EAD na tentativa de expandir o ensino superior ao maior número de pessoas possíveis, mas sem uma avaliação sistemática de como está o seu desenvolvimento.

Sob o aspecto ilusório da expansão do acesso, essa estratégia tem sido sustentada por setores dominantes da sociedade, que obtêm lucro imediato nessa configuração de adestramento da força de trabalho. Mas tem sido preocupante também o apelo popular que difunde de forma acrítica e passiva esse processo de perda total do sentido e das possibilidades da educação e da formação em seu sentido mais amplo (civilizatório e emancipatório) (Associação Brasileira de Ensino e Pesquisa em Serviço Social, 2011, p. 787).

Pelo exposto, muitos são os descompassos existentes entre a academia e os serviços, quando se trata da graduação na área da saúde. Desse modo, os estudos apresentados reafirmam a necessidade urgente de repensar os modos de formação dos alunos para que, egressos de seus cursos, sejam cidadãos capazes de exercer suas atividades profissionais fundamentadas em princípios éticos, valores solidários, excelência acadêmica e em consonância com as necessidades da sociedade.

\section{Conclusões}

Os estudos que serviram para a construção desta revisão apontam o ensino superior como um campo de efervescência, com posições que ora convergem e ora divergem. Há contraditórios em relação às metodologias de ensino, com a necessidade de um olhar crítico sobre elas para que se traduzam em 
uma formação em saúde, respondendo aos anseios da sociedade. Contudo, de modo geral, houve consenso em relação à teoria caminhando com a prática, conduzindo a uma formação por competências. Esta também envolve os professores, dos quais são exigidas competências para ensinar. Apesar disso, a valorização maior da pesquisa, como vem ocorrendo no Brasil, mostra a formação pedagógica docente como um nó crítico.

Apesar da existência de experiências que promovam uma educação emancipatória, voltada aos serviços e consoante as DCN, nos textos houve menção massiva de que a academia, de modo geral, ainda persiste na formação a partir de modelos tradicionais que no passado serviam bem ao contexto de suas épocas, mas hoje requerem reelaborações, extrapolando o enfoque biológico, com as sociedades se coresponsabilizando pelo cuidado. Nesse ponto de vista, metodologias como a problematização e a Aprendizagem Baseada em Problemas ganham importância porque levam o estudante a considerar primeiro a ótica do outro para então traçar estratégias de promoção/proteção da saúde e prevenção de doenças.

Para que tais metodologias se consolidem de fato nas IES é ainda premente o apoio de seus dirigentes e de toda a comunidade acadêmica. $\mathrm{O}$ problema é que muitos educadores preferem não deixar a sua zona de conforto, de ensinar intramuros universitários, em situação controlada. Falta a alguns o exercício autocrítico para a mudança de postura porque já estão 'enformados' no tradicionalismo.

Assim, é necessário formar o docente para educar porque não são meramente títulos ou números de publicações que o transformarão em um docente competente. Adentramos então outro problema. As agências de fomento ligadas à educação não têm investido no campo do preparo dos docentes. Supervalorizam a pesquisa, mas deixam a desejar no tocante ao ensino e à extensão, quando todos deveriam caminhar conjuntamente.

Vê-se, portanto, que as metodologias não devem parar no tempo, e sim surgirem e ressurgirem acompanhando as transformações mundiais e locorregionais. Inovar, crescer e avançar somente é possível a partir de esforços coletivos, e é hora de se pensar para onde a graduação em saúde no Brasil deseja caminhar. É preciso avançar na área, mediante debates de modo a socializar experiências e ideias para a formação de profissionais nesse importante campo do conhecimento que deem respostas às necessidades sociais. 


\section{Colaboradores}

Iramara Lima Ribeiro trabalhou na concepção do artigo, pesquisa de referencial teórico, redação e revisão crítica. Antônio Medeiros Júnior colaborou na concepção e na revisão crítica. Declaramos que não há conflitos de interesse.

Resumen La enseñanza superior en salud ejerce un papel fundamental en la sociedad porque los egresados de los cursos ofrecidos en el área serán los futuros prestadores de asistencia a la población. El objetivo de este estudio fue analizar publicaciones en la literatura a respecto de la graduación en el área de la salud, cuya metodología fue una revisión narrativa, con 51 materiales seleccionados en la base de datos de la Biblioteca Virtual en Salud (centrados en la graduación, metodologías de enseñanza y relación teoría-práctica). Los resultados mostraron la importancia de aunar teoría y práctica, y las divergencias con relación a las metodologías de enseñanza, necesitando una mirada crítica sobre éstas, además de las fragilidades en la formación pedagógica de docentes. Se concluye que el disenso con relación a las metodologías de enseñanza y la preocupación con la formación de discentes y docentes muestra la necesidad de realizar debates a fin de socializar experiencias e ideas en este importante campo del conocimiento, que den respuestas a las necesidades sociales.

Palabras clave enseñanza superior; instituciones de enseñanza superior; atención a la salud.

\section{Notas}

1 Universidade Federal do Rio Grande do Norte, Departamento de Saúde Coletiva, Programa de Pós-Graduação em Saúde Coletiva, Natal, Rio Grande do Norte, Brasil.

<iramararibeiro@hotmail.com>

Correspondência: Avenida Senador Salgado Filho, 3000, Campus Universitário Central, Lagoa Nova, CEP 59078-970, Natal, Rio Grande do Norte, Brasil.

2 Universidade Federal do Rio Grande do Norte, Departamento de Saúde Coletiva, Programa de Pós-Graduação em Saúde Coletiva, Natal, Rio Grande do Norte, Brasil. <amjunior@ufrnet.br>

3 Este artigo é resultado de pesquisa de revisão bibliográfica realizada no âmbito da dissertação de mestrado intitulada Aprendizagem na interação ensino-serviço-comunidade: a formação na perspectiva dialógica com a sociedade, de autoria de Iramara Lima Ribeiro, a quem foi concedida uma bolsa pelo Conselho Nacional de Desenvolvimento Científico e Tecnológico (CNPq). 


\section{Referências}

ASSOCIAÇÃO BRASILEIRA DE ENSINO E PESQUISA EM SERVIÇO SOCIAL. Conselho Federal de Serviço Social. As entidades do Serviço Social brasileiro na defesa da formação profissional e do projeto ético-político. Serviço Social \& Sociedade, São Paulo, n. 108, p. 785-802, 2011.

BAGNATO, Maria H.S.; RODRIGUES, Rosa M. Diretrizes Curriculares da Graduação de Enfermagem: pensando contextos, mudanças e perspectivas. Revista Brasileira de Enfermagem, Brasília, v. 60, n. 5, p. 507-512, 2007.

BARBA, Patrícia C. S. D. et al. Formação inovadora em Terapia Ocupacional. Interface: Comunicação, Saúde, Educação, Botucatu, v. 16, n. 42, p. 829-842, 2012.

BERNARDO, Wanderley M.; NOBRE, Moacyr R. C; JATENE, Fábio B. A prática clínica baseada em evidências: parte II - buscando as evidências em fontes de informação. Revista da Associação Médica Brasileira, São Paulo, v. 50, n. 1, p. 104-108, 2004.

BICALHO, Rute N.M.; OLIVEIRA, Maria C. S. L. O processo dialógico de construção do conhecimento em fóruns de discussão. Interface: Comunicação, Saúde, Educação, Botucatu, v. 16, n. 41, p. 469-483, 2012.

BIREME (Brasil). Biblioteca Virtual em Saúde. Tutorial de pesquisa bibliográfica. São Paulo: Bireme, 2009.

BRASIL. Lei n. 9.394, de 20 de dezembro de 1996. Estabelece as diretrizes e bases da educação nacional. Diário Oficial [da] República Federativa do Brasil. Poder Executivo, Brasília, DF, 23 de dez. 1996, n. 248, Seção 1, p. $27.833-41$

BRASIL. Ministério da Educação. Secretaria de Educação Superior. Programas e ações. 2014. Disponível em: <http://portal.mec.gov. br/index.php?option $=$ com_content\&view $=$ article $\& i d=12498 \&$ Itemid $=820>$. Acesso em: 22 jan. 2014.
BRUZOS, Gabriela A. S. et al. Meio ambiente e enfermagem: suas interfaces e inserção no ensino de graduação. Saúde e Sociedade, São Paulo, v. 20, n. 2, p. 462-469, 2011.

CALDERÓN, Adolfo I. Terceirização do trabalho docente à luz da responsabilidade social da educação superior. Trabalho, Educação e Saúde, Rio de Janeiro, v. 11 n. 3, p. 487-501, 2013.

CALDERÓN, Adolfo I.; PEDRO, Rodrigo F.; VARGAS, Maria C. Responsabilidade social da educação superior: a metamorfose do discurso da Unesco em foco. Interface: Comunicação, Saúde, Educação, Botucatu, v. 15, n. 39, p. 1.185-1.198, 2011.

CAMPONOGARA, Silviamar et al. Responsabilidade ambiental na visão de acadêmicos da área da saúde. Revista Enfermagem UERJ, Rio de Janeiro, v. 20, n. 1, p. 39-44, 2012.

CANALLI, Cláudia S. E. et al. A humanização na odontologia: uma reflexão sobre a prática educativa. Revista Brasileira de Odontologia, Rio de Janeiro, v. 68, n. 1, p. 44-48, 2011.

CARDOSO, Fátima A. et al. Capacitação de agentes comunitários de saúde: experiência de ensino e prática com alunos de Enfermagem. Revista Brasileira de Enfermagem, Brasília, v. 64, n. 5, p. 968-973, 2011.

COLOSSI, Nelson; CONSENTINO, Aldo; QUEIROZ, Etty G. Mudanças no contexto do ensino superior no Brasil: uma tendência ao ensino colaborativo. Revista da FAE, Curitiba, v. 4, n. 1, p. 51-58, 2001.

CONTERNO, Solange F. R; LOPES, Roseli E. Inovações do século passado: origens dos referenciais pedagógicos na formação profissional em saúde. Trabalho, Educação e Saúde, Rio de Janeiro, v. 11 n. 3, p. 503-23, 2013.

CORREIA, Aline A. et al. Necessidades dos serviços e exigências da academia: uma ar- 
ticulação possível. Revista Brasileira de Ciências da Saúde, João Pessoa, v. 13, n. 1, p. 7-12, 2009.

COSTA, Caetano da; CASAGRANDE, Lisete D. R.; UETA, Julieta. Processos reflexivos e competências envolvidos na prática docente universitária: um estudo de caso. Interface: Comunicação, Saúde, Educação, Botucatu, v. 13, n. 31, p. 409-422, 2009.

CYRINO, Eliana G.; TORALLES-PEREIRA, Maria L. Trabalhando com estratégias de ensino-aprendizado por descoberta na área da saúde: a problematização e a aprendizagem baseada em problemas. Cadernos de Saúde Pública, Rio de Janeiro, v. 20, n. 3, p. 780-788, 2004.

DIAS, Henrique S. A implementação da política de reorientação da formação em Odontologia: dependência de trajetória e estímulos institucionais na UFBA. Dissertação (Mestrado em Ciências na Área de Saúde Pública) - Escola Nacional de Saúde Pública Sergio Arouca, Rio de Janeiro, 2011.

DURÁN GONZÁLEZ, Alberto; ALMEIDA, Márcio J. Onde nascem e como se concretizam as mudanças na formação superior da área da saúde? Espaço Saúde (on line), Londrina, v. 10, n. 1, p. 25-33, 2008.

EDER, Maria L.; SCHWARTZMAN, Gisela. Formar o recetar: el aporte de la asesoría pedagógica para transformar las prácticas docentes. Revista del Hospital Italiano de Buenos Aires, Buenos Aires, v. 31, n. 3, p. 93-98, 2011.

FERNANDES, Josicélia D. et al. Diretrizes curriculares e estratégias para implantação de uma nova proposta pedagógica. Revista da Escola de Enfermagem da USP, São Paulo, v. 39, n. 4, p. 443-449, 2005.

FORMIGA, Nicéia F. B.; RIBEIRO, Kátia S. Q. S. Inserção do fisioterapeuta na Atenção Básica: uma analogia entre experiências acadêmicas e a proposta dos Núcleos de Apoio à Saúde da Família (NASF). Revista Brasileira de Ciências da Saúde, João Pessoa, v. 16, n. 2, p. 113-122, 2012.
FRANCISCHETTI, Ieda et al. Role-playing: estratégia inovadora na capacitação docente para o processo tutorial. Interface: Comunicação, Saúde, Educação, Botucatu, v. 15, n. 39, p.1207-18, 2011.

FRANCO, Ana C.; BOOG, Maria C.F. Relação teoria-prática no ensino de educação nutricional. Revista de Nutrição, Campinas, v. 20, n. 6, p. 643-655, 2007.

FRANCO, Alexandre P. Ensino superior no Brasil: cenário, avanços e contradições. Jornal de Politicas Educacionais, Curitiba, n. 4, p. 53-63, 2008.

GARCIA, Maria A. A.; SILVA, Ana L. B. Um perfil do docente de Medicina e sua participação na reestruturação curricular. Revista Brasileira de Educação Médica, Rio de Janeiro, v. 35, n. 1, p. 58-68, 2011.

GIROUX, Henry. Ensino superior, para quê? Educar, Curitiba, n. 37, p. 25-38, 2010.

GOMES, Andréia P. (Trans)Formação da educação médica: é possível mudar o perfil do egresso com base em modificações no método de ensino-aprendizagem? Tese (Doutorado em Ciências na Área de Saúde Pública) - Escola Nacional de Saúde Pública Sergio Arouca, Rio de Janeiro, 2011.

GOMES, Jomara B.; CASAGRANDE, Lisete D. R. A educação reflexiva na pós-modernidade: uma revisão bibliográfica. Revista Latino-Americana de Enfermagem, Ribeirão Preto, v. 10, n. 5, p. 696-703, 2002.

HINOJO, Maria A.; FERNÁNDEZ, Andrés. El aprendizaje semipresencial o virtual: nueva metodología de aprendizaje en Educación Superior. Revista Latinoamericana de Ciencias Sociales, Niñez y Juventud, Manizales, v. 10, n. 1, p. 159-167, 2012.

KLEGERIS, Andis; HURREN, Heather. Impact of problem-based learning in a large classroom setting: student perception and problem-solving skills. Advances in Physiology Education, Bethesda, v. 35, n. 4, p. 408-415, 2011. 
KRUSE, Maria H. L. É possível pensar de outro modo a educação em Enfermagem? Escola Anna Nery Revista de Enfermagem, Rio de Janeiro, v. 12, n. 2, p. 348-352, 2008.

LEMOS, Marcio; BAZZO, Leda M. F. Formação do fonoaudiólogo no município de Salvador e consolidação do SUS. Ciência \& Saúde Coletiva, Rio de Janeiro, v. 15, n. 5, p. 2.563-2.568, 2010.

LIMA, Juliana O. R. et al. A formação ético-humanista do enfermeiro: um olhar para os projetos pedagógicos dos cursos de graduação em enfermagem de Goiânia, Brasil. Interface: Comunicação, Saúde, Educação, Botucatu, v.15, n.39, p.1111-25, 2011.

LUZ, Sueli P.; BALZAN, Newton C. Programa de formação continuada para docentes da educação superior: um estudo avaliativo a partir dos resultados de uma tese. Avaliação, Campinas, Sorocaba, v. 17, n. 1, p. 11-41, 2012.

MACHADO, José L. M.; MACHADO, Valéria M.; VIEIRA, Joaquim E. Formação e seleção de docentes para currículos inovadores na graduação em saúde. Revista Brasileira de Educação Médica, Rio de Janeiro, v. 35, n. 3, p. 326-333, 2011.

MARSDEN, Melissa. A indissociabilidade entre teoria e prática: experiências de ensino na formação de profissionais de saúde nos níveis superior e médio. Dissertação (Mestrado em Ciências na Área de Saúde Pública) - Escola Nacional de Saúde Pública Sergio Arouca, Rio de Janeiro, 2009.

MARTINS, Antonio C. P. Ensino superior no Brasil: da descoberta aos dias atuais. Acta Cirurgica Brasileira (on line), São Paulo, v. 17, supl. 3, p. 4-6, 2002.

MENDES, Layza C. B.; CAPRARA, Andrea. Bacharelado interdisciplinar em saúde: análise preliminar de um novo currículo de ensino superior no Brasil. Interface: Comunicação, Saúde, Educação, Botucatu, v. 16, n. 42, p. 719-31, 2012.

MORAES, Juliano T.; LOPES, Eliane M.T. A formação de profissionais de saúde em insti- tuições de ensino superior de Divinópolis, Minas Gerais. Trabalho, Educação e Saúde, Rio de Janeiro, v. 7, n. 3, p. 435-444, 2009-2010.

MURRAIN KNUDSON, Elizabeth. La universidad: ¿Un escenario para transformar la conciencia social de los profesionales? Revista Repertorio de Medicina y Cirurgía, Bogotá, v. 18, n. 1, p. 29-35, 2009.

NASCIMENTO, Elvia L. A.; VIEIRA, Sarita B.; ARAÚJO, Anísio J. S. Desafios da gestão coletiva da atividade na docência universitária. Psicologia Ciência e Profissão, Brasília, v. 32, n. 4, p. 840-855, 2012.

NÓBREGA-THERRIEN, Sílvia M.; FEITOSA, Laura M. Ação formativa e o desafio para a graduação em saúde. Revista Brasileira de Educação Médica, Rio de Janeiro, v. 34, n. 2, p. 227-237, 2010.

NUNES, Emanuelle C. D. A.; SILVA, Luzia W. S.; PIRES, Eulina P. O. R. O ensino superior de Enfermagem: implicações da formação profissional para o cuidado transpessoal. Revista Latino-Americana de Enfermagem, Ribeirão Preto, v. 19, n. 2, p. 252-260, 2011.

OLIVEIRA, Gilson S.; KOIFMAN, Lilian. Uma reflexão sobre os múltiplos sentidos da docência em saúde. Interface: Comunicação, Saúde, Educação, Botucatu, v. 17, n. 44, p. 211-218, 2013.

OLIVEIRA, Cláudia C.; VASCONCELLOS, Maura M. M. A formação pedagógica institucional para a docência na Educação Superior. Interface: Comunicação, Saúde, Educação, Botucatu, v. 15, n. 39, p. 1.011-1.024, 2011.

PATRÍCIO, Zuleica M. Sistematização de estratégias de ensinar-aprender pesquisa na graduação. Interface: Comunicação, Saúde, Educação, Botucatu, v. 15, n. 39, p. 1.159-1.172, 2011.

PEREIRA, Juliana G. et al. Integração academia, serviço e comunidade: um relato de experiência do curso de graduação em Medicina na Atenção Básica no município de São Paulo. Mundo Saúde, São Paulo, v. 33, n. 1, p. 99-107, 2009. 
PEREIRA, Sueli E. Contribuições para um planejamento educacional em ciências da saúde com estratégias inovadoras de ensino-aprendizagem. Comunicação em Ciências da Saúde, Brasília, v. 18, n. 1, p. 33-44, 2007.

PEREIRA, Wilza R. Entre a dominação simbólica e a emancipação política no ensino superior em Enfermagem. Revista da Escola de Enfermagem da USP, São Paulo, v. 45, n. 4, p. 981-988, 2011.

POCINHO, Margarida; FRAGOEIRO, Joana G. Satisfação dos docentes do ensino superior. Acta Colombiana de Psicología, Bogotá, v. 15 n. 1, p. 87-97, 2012.

RODRIGUES, Cae. A ambientalização dos currículos de Educação Física no ensino superior. Motriz, Rio Claro, v. 18 n. 3, p. 557-570, 2012.

ROJO, Priscila T. et al. Panorama da educação à distância em Enfermagem no Brasil. Revista da Escola de Enfermagem da USP, São Paulo, v. 45, n. 6, p. 1.476-1.480, 2011.

SILVA, Ana P. S. A enfermeira e a corresponsabilidade pela formação do aluno no estágio curricular. Tese (Doutorado em Enfermagem) - Universidade Federal do Rio Grande do Sul, Porto Alegre, 2012.

SILVA, Kênia L. et al. Desafios da formação do enfermeiro no contexto da expansão do ensino superior. Escola Anna Nery Revista de Enfermagem, Rio de Janeiro, v. 16, n. 2, p. 380-387, 2012.

SILVA, Marcos A. M. et al. O Pró-Saúde e o incentivo à inclusão de espaços diferenciados de aprendizagem nos cursos de odontologia no Brasil. Interface: Comunicação, Saúde, Educação, Botucatu, v. 16, n. 42, p. 707-717, 2012.

SILVA, Rinaldo H. A.; MIGUEL, Soraida S.; TEIXEIRA, Luciana S. Problematização como método ativo de ensino-aprendizagem: estudantes de Farmácia em cenários de prática.
Trabalho, Educação e Saúde (on line), Rio de Janeiro, v. 9, n. 1, p. 77-93, 2011.

SOARES, Nadia T.; AGUIAR, Adriana C. Diretrizes curriculares nacionais para os cursos de Nutrição: avanços, lacunas, ambiguidades e perspectivas. Revista de Nutrição, Campinas, v. 23, n. 5, p. 895-905, 2010.

TEIXEIRA, Carmem F. S; COELHO, Maria T. A. D.; ROCHA, Marcelo N. D. Bacharelado interdisciplinar: uma proposta inovadora na educação superior em saúde no Brasil. Ciência \& Saúde Coletiva, Rio de Janeiro, v. 18, n. 6, p. 1.635-1.646, 2013.

TOASSI, Ramona F. C. et al. Currículo integrado no ensino de Odontologia: novos sentidos para a formação na área da saúde. Interface: Comunicação, Saúde, Educação, Botucatu, v. 16, n. 41, p. 529-542, 2012.

TRAJMAN, Anete et al. A preceptoria na rede básica da Secretaria Municipal de Saúde do Rio de Janeiro: opinião dos profissionais de saúde. Revista Brasileira de Educação Médica, Rio de Janeiro, v. 33, n. 1, p. 24-32, 2009.

VIEIRA, Diana A.; CAIRES, Susana; COIMBRA, Joaquim L. Do ensino superior para o trabalho: contributo dos estágios para inserção profissional. Revista Brasileira de Orientação Profissional, São Paulo, v. 12, n. 1, p. 29-36, 2011.

VILARDO, Claudia O. L. Formação médica e promoção da saúde de comunidades: a articulação dessas práticas em um mesmo cenário. Dissertação (Mestrado em Ciências na Área de Saúde Pública) - Escola Nacional de Saúde Pública Sergio Arouca, Rio de Janeiro, 2011.

XAVIER, Alex S.; KOIFMAN, Lilian. Educação superior no Brasil e a formação dos profissionais de saúde com ênfase no envelhecimento. Interface: Comunicação, Saúde, Educação, Botucatu, v. 15, n. 39, p. 973-984, 2011.

Recebido em 02/07/2013

Aprovado em 19/09/2014 